\title{
Diagnostic utility of various techniques used in body fluid cytology
}

\author{
Dr.Archana Joshi,Associate Professor.,Dr.Nidhi Mahajan, Asstt.Lecturer. \\ Dr.P.J. Karmarkar, Asso.Prof.,Dr.S.D.Mahore, Professor \\ Department of Pathology,N.K.P.Salve Institute of Medical Sciences, Hingana Road,Nagpur-19 (M.S.) India
}

\begin{abstract}
Background-The cytological examinations of serous effusions have been well accepted, and a positive diagnosis is often considered as a definitive diagnosis. It helps in staging, prognosis and management of patients of malignancies, and also give information about various inflammatory and non inflammatory lesions. Diagnostic problem arises in everyday practice to differentiate reactive atypical mesothelial cells from malignant cells by routine conventional smear method.

Aim- To compare the morphological features of the conventional smear method with those of cytospin(cytocentrifuge) and cell block and also to assess the utility and sensitivity of cytospin and cell block methods in the cytodiagnosis of effusion.

Material and method- One hundred and fifty samples were subjected to diagnostic evaluation. Along with conventional smear, fluids were subjected to cytocentrifuge and cell block technique. Cell blocks were prepared using 10\%formal alcohol as a fixative agent. Smears obtained by each of techniques were scored for different parameters. Statistical analysis with Wilcoxon rank sum test was performed and also Index of Qualitative Variation(IQV) was calculated to compare the results obtained by each of the above three methods. Results- Cellularity and additional yield for malignancy was more for Cytospin and Cell Block technique.

Conclusion- The cytospin and cell block method provide high cellularity, better architectural patterns, morphological features and an additional yield of malignant cells, and thereby, increases the sensitivity of the cytodiagnosis when compared to conventional smear method.
\end{abstract}

Keywords: Cytospin, Cell block, conventional smear,fluid cytology

\section{Introduction}

Cytological examination of serous effusions have been done for nearly a century in the diagnosis of malignancy and eventually in the detection of primary lesions.It has helped for staging and prognosis of the malignant tumors and also gave information regarding various inflammatory lesions of serous membranes. ${ }^{[1]}$ It has gained increased acceptance to such an extent that a positive diagnosis was often considered as a definitive diagnosis. $^{[1]}$

Thus cytological study of body effusions is a complete diagnostic modality which aims at pointing out the etiology of effusion as well as in certain cases a means of prognostication of the disease process. The diagnostic performance of the cytologic study of the fluid may be attributable to the fact that the cell population present in sediment is representative of a much larger surface area than that obtained by needle biopsy. ${ }^{[2]}$ Aspiration of serous cavities is a simple and relatively simple technique to achieve a diagnosis.

Except in few institutes, there is no standard technique for processing these fluids, that is reliable and cost effective. The technique still widely used in most cytology laboratory of India is the centrifugation and sedimentation smear preparation technique. With this technique, failure of collecting relatively few cells from any fluid and keeping them on the slide during staining is responsible for large number of unsatisfactory smear. Thus resulting in effusion being reported as negative or atypical without definitive diagnosis and false negative diagnosis.

This study familiarise with the efficacy and utility of various techniques in the study of effusion which includes conventional smear(routine centrifuge),cytocentrifuge(cytospin) and cell block technique.

\section{Material and Methods}

The present study is prospective study carried out in the department of Pathology over a period of two years.

Inclusion criteria:Cellular effusions comprising of pleural,peritoneal,pericardial fluids were included.

Exclusion criteria:All body fluids other than pleural,peritoneal and pericardial fluids were excluded.

Sample size:All one hundred and fifty cellular samples comprising of pleural,peritoneal and pericardial fluids received over a period two years in the department of Pathology were the subject of study. 
The fresh samples obtained were examined by naked eye for physical characteristic and then divided into three equal parts.One part was subjected to routine centrifuge practiced in our laboratory i.e. thick and thin smear preparation after centrifugation at 1500rpm for 15 minutes. Other part was subjected to cytocentrifuge i.e. 300 microlitre of fluid was placed in cytospin funnel with the filter paper placed between the slide and the funnel, then subjected to centrifugation at $700 \mathrm{rpm}$ for 6 minutes. The slide was then fixed in $95 \%$ ethanol for 15 minutes and stained with haematoxylin and eosin;and the third part for cell block technique. The third part of the fluid was fixed in 10\% formal alcohol in the ratio of 1:1 and kept for 1 hour. After fixation it was centrifuged at $2000 \mathrm{rpm}$ for 10 minutes. The supernatant was poured off and the cell button formed was obtained on Whatman filter paper number 1 . The sediment was wrapped in the same filter paper and processed in histokinette and embedded in paraffin. Sections were cut at 5micro $\mathrm{m}$ and stained with haematoxylin and eosin.

The smears obtained by each of the above technique were evaluated for features such as background, cellularity, cell morphology and cell distribution and were scored from 0 to 2+ scale (Table-1) according to the Mair et el scoring system. ${ }^{[3]}$

\begin{tabular}{|c|c|c|}
\hline PARAMETER & QUANTITATIVE DESCRIPTION & POINT SCORE \\
\hline $\begin{array}{l}\text { 1.Background blood or } \\
\text { proteinaceous material }\end{array}$ & $\begin{array}{l}\text { 1.Largeamount, great compromise in diagnosis. } \\
\text { 2.Modearteamount,diagnosis possible. } \\
\text { 3.Minimal,diagnosis easy. }\end{array}$ & $\begin{array}{l}0 \\
1 \\
2\end{array}$ \\
\hline 2.Amount of cellular material & $\begin{array}{l}\text { 1.Minimal to absent,diagnosis not possible. } \\
\text { 2.Sufficient for cytodiagnosis. } \\
\text { 3.Abundant,diagnosis simple. }\end{array}$ & $\begin{array}{l}0 \\
1 \\
2\end{array}$ \\
\hline $\begin{array}{l}\text { 3.Cell morphology,cellular } \\
\text { degeneration and trauma }\end{array}$ & $\begin{array}{l}\text { 1.Marked cellular degeneration,diagnosis not possible. } \\
\text { 2.Moderate cellular degeneration,diagnosis possible. } \\
\text { 3.Minimal cellular degeration,diagnosis easy. }\end{array}$ & $\begin{array}{l}0 \\
1 \\
2\end{array}$ \\
\hline 4.Distribution of cells & $\begin{array}{l}\text { 1.Totally in the periphery or sparsely distributed. } \\
\text { 2.Combination. } \\
\text { 3.Evenly distributed. }\end{array}$ & $\begin{array}{l}0 \\
1 \\
2\end{array}$ \\
\hline
\end{tabular}

Statistical analysis: Wilcoxon rank sum test was used to determine the statistical significance of difference of each parameter between two methods.

For comparing the median score of three groups Kruskal -Wallis test was used.

\section{Results}

One hundred and fifty effusion samples were subjected to routine centrifuge, cytospin and cell block. The most common effusion was peritoneal(53.33\%) followed by pleural $(44.67 \%)$ and pericardial $(2 \%)$.Male preponderance of effusion was seen,the male to female ration being 1.05:1. Maximum number of cases were in the age group of 41-60 years and the least in the age group of 81-100years

Of the 150 cases, 116(77.33\%) were non neoplastic effuison and 34(22.66\%) were neoplastic effusion. Of the non neoplastic effusions, most common cytological diagnosis was chronic inflammation(43.10\%) followed by mixed inflammation (23.28\%), reactive effusion (20.69\%), acute inflammation(8.62\%), eosinophilic effusion $(1.72 \%)$ and miscellaneous $(2.59 \%)$. The majority of cases of non neoplastic effusion were due to lung pathology which includes tuberculosis and pneumonia. Other causes include cirrhosis of liver, infection of GIT and ovarian neoplasm, pulmonary infarction and traumatic irritation. One case of eosinophilic effusions were due to trauma and other was diagnosed as Pulmonary Eosinophilic Syndrome. Two cases of pleural effusion were due to fungal infection. One showed multiple delicate candidal hyphae and other showed narrowly budding yeast of Cryptococcus Neoformans.One case of pleural effusion due to oesophageal fistulous tract showed vegetative matter.

Of the 34 cytologically neoplastic effusion, 19(55.88\%) were peritoneal effusion, $13(38.23 \%)$ were pleural effusion and 2(5.88\%) were pericardial effusion. Maximum number of cases were in the age group of 21-40 years. Male preponderance was seen with male to female ratio being 1.13:1. Most of the cases of malignant peritoneal effusion were due to GIT and ovarian malignancies and malignant pleural effusion were due to breast and lung malignancies.

In the present study, of 34 cases of malignant effusion, 14 were reported as positive for malignancy, 15 showed atypical cells suspicious of malignancy on routine centrifuge.(Fig.1)Out of the 14 malignant effusions, 4 were reported as epithelial malignancy.However cytocentrifuge and cell block method were positive for malignant cells for all 34 cases(Table-2). 
Table-2 Distribution of malignant cases diagnosed by various techniques

\begin{tabular}{|c|c|c|}
\hline Malignant cases & On routine centrifuge & On cytospin and cell block \\
\hline 34 & 14 & 34 \\
\hline
\end{tabular}

Thus 5 malignant effusions were missed on routine centrifuge. Also the 4 cases reported as epithelial malignancy on centrifuge, showed better architectural pattern on cytocentrifuge and cell block(Fig.2) and a specific diagnosis of adenocarcinoma was made.(Fig.3) Thus adenocarcinoma was dignosed in 28 cases. 2 cases on NHL, 2 cases of Mesothelioma. 1 case of SCC and 1 case of CLL/SLL was seen. It was found that there was significant difference between the results obtained by routine centrifugeas compared to cytocentrifuge and cell block.

In evaluating the cytological details brought out by each technique, cytospin was superior in demonstrating cellularity, cell retrival, less cellular crowding, better cytoplasmic and nuclear preservation than routine method.Sections prepared from cell block showed good architectural pattern (cell balls, acinar pattern, papillary structures). Nuclear and cytoplasmic preservations were as good as compared to cytospin.

Various statistical tests were applied on the data obtained and the results were compared.

(Table-3\&4)

Table 3: Descriptive statistics for each of the four parameters by method of routine centrifuge, cytospin and cell block

\begin{tabular}{|l|l|l|l|l|}
\hline Method & Parameter & Mean \pm SD (Median) & IQV & \\
\hline \multirow{4}{*}{ CENTRIFUGE } & Background & $0.553 \pm 0.55(1)$ & 0.7879 & \\
\cline { 2 - 6 } & Cellularity & $0.89 \pm 0.40(1)$ & 0.4439 & \\
\cline { 2 - 6 } & Cell morphology & $0.61 \pm 0.55(1)$ & 0.7879 & \\
\cline { 2 - 6 } & Cell distribution & $0.69 \pm 0.55(1)$ & 0.7583 & \\
\hline \multirow{5}{*}{ CYTOSPIN } & Background & $1.99 \pm 0.12(2)$ & 0.0395 & \\
\cline { 2 - 6 } & Cellularity & $1.99 \pm 0.12(2)$ & 0.0395 & \\
\cline { 2 - 6 } & Cell morphology & $1.99 \pm 0.08(2)$ & 0.0199 & \\
\cline { 2 - 6 } & Cell distribution & $1.98 \pm 0.14(2)$ & 0.0588 & \\
\hline & Background & $2(2)$ & 0.0000 & \\
\cline { 2 - 6 } & Cellularity & $1.99 \pm 0.08(2)$ & 0.0199 & \\
\cline { 2 - 6 } & Cell morphology & $2(2)$ & 0.0000 & \\
\cline { 2 - 6 } & Cell distribution & $2(2)$ & 0.0000 & \\
\hline
\end{tabular}

IQV (Index of Qualitative Variation) ranges from 0 (No variation) to 1(Maximum variation) IQV was found minimum for parameters in CELL BLOCK

Table 4 : Statistical significance of difference of each parameter each of the four parameters across different comparisons of methods

\begin{tabular}{|l|l|l|l|l|}
\hline \multirow{2}{*}{ Parameter } & \multicolumn{4}{|c|}{ Comparison of methods } \\
\cline { 2 - 5 } & $\begin{array}{l}\text { Centrifuge, Cytospin\& Cell } \\
\text { block* }\end{array}$ & $\begin{array}{l}\text { Centrifuge } \\
\& \text { Cytospin** }\end{array}$ & $\begin{array}{l}\text { Centrifuge \& } \\
\text { Cell block** }\end{array}$ & Cytospin\& Cell block** \\
\hline Background & $<0.0001$ & $<0.0001$ & $<0.0001$ & 0.158 \\
\hline Cellularity & $<0.0001$ & $<0.0001$ & $<0.0001$ & 0.565 \\
\hline $\begin{array}{l}\text { Cell } \\
\text { morphology }\end{array}$ & $<0.0001$ & $<0.0001$ & $<0.0001$ & 0.321 \\
\hline $\begin{array}{l}\text { Cell } \\
\text { distribution }\end{array}$ & $<0.0001$ & $<0.0001$ & $<0.0001$ & 0.082 \\
\hline
\end{tabular}

*Significance of difference of each parameter for three groups was performed using Kruskal Wallis test. ** Significance of difference of each parameter for two groups was performed using Wilcoxon rank sum test. Kruskal Wallis test indicated statistically significant difference of median score for each parameter $(p<0.0001)$ across three methods. The two group comparison was performed using Wilcoxon rank sum test. It revealed that difference of median scores for Centrifuge \&Cytospin as well as Centrifuge \& Cell block on each parameter were statistically significant $(p<0.0001)$. However, the difference between Cytospin\& Cell block on each parameter was statistically insignificant $(p>0.05)$.

\section{Discussion}

The cytological examination of serous effusions has increasingly gained acceptance in clinical medicine,to such an extent that a positive diagnosis is often considered the definitive test and obviates explorative surgery.It is important not only in the diagnosis of malignant lesions, but also help in staging and prognosis. $^{[6]}$

In most of the cytology laboratories,cytologist prefer direct smear prepared from centrifuged deposits of effusion.The cell block technique which is amongst the oldest method of processing cytological material for 
microscopy has been abandoned by many laboratories as several alternative excellent cell preparation methods have been developed. ${ }^{[7]}$ However several authors have reported the advantages of cell blocks in cytology which includes valuable diagnostic evidence that can be observed in smears.

Lack of morphological details of the representative cells contributes to considerable difficulties in making conclusive diagnosis on conventional smears. In order to overcome these difficulties,in this study an attempt was made to prepare and analyse routine centrifuge, cytocentrifuge and cell block from the same sample. In this study due consideration was given to age, sex, site of effusion, clinical findings and investiagtions to arrive at final diagnosis and also to identify primary malignant lesion.

The use of cytocentrifuge and cell block not only increases the cellularity as compared to routine centrifuge, but also the cells were evenly distributed.The cellular morphology,nuclear and cytoplasmic details, were better appreciated on cytocentrifuge and cell block technique.Also cell block carries additional advantage of performing Immunohistochemistry which aids in the diagnosis and can be used for retrospective analysis. ${ }^{[8]}$ During the preparation of cytocentrifuge smears, cells are subjected to a centrifugal force, and subsequent flattening of cells on to the glass slide would be expected to result in increased cellular area measurement. ${ }^{[9]}$ The influence of centrifugal forces on cells tends to accentuate subtle variations in nuclear shape, and as a result nuclear invaginations are more easily discerned.The presence of artifactual distortion of cells during cytocentrifuge cannot be discounted;this may,however,be minimized by preparing smears at a low centrifugation speed. ${ }^{[9]}$ The degree of irregularity of the nuclear contour was more easily appreciated on cytocentrifuge preparation as compared to conventional smear. ${ }^{[10]}$ Thus routine centrifuge exhibits poor sensitivity and are less often positive than cytospin smears. ${ }^{[11,12]}$

Reactive mesothelial cells have been responsible for stimulating malignancy in conventional smear, largely due to formation rosette,pseudoacini or acini,with or without the presence of prominent nucleoli. ${ }^{[13,14,15]}$ The cell block effectively puts both the features in their proper prospective:That is nucleoli do not appear as prominent as in conventional smear, and the pseudoacinar and acinar pattern can be better appreciated when,in the cell block.Similar findings were noticed in Dekker and Bupp study. ${ }^{[16]}$ Cell Block is a valuable tool in the evaluation of well differentiated adenocarcinoma such as tumors of the breast,lung or gasatrointestinasl tract.These tumors have few malignant characters in conventional centrifuge, while the presence of true acini is seen in cell block,together with mucin.The other advantage of cell block is concentration of cellular material in one small area that can be evaluated at a glance with all cells lying in the same focal plane of the microscope.It bridges the gap between cytology and histology. ${ }^{[6]}$

Also the cellularity was more by cell block method as compared to routine centrifuge method.Architectural pattern such as glands, sheets, clusters and cell balls were commonly observed in cell block method, whereas, singly scattered cells were prominent findings in routine centrifuge.These findings are consistent with the findings in the study done by Udasimath $\mathrm{S}$ et al ${ }^{[6]}$.

A wide range of fixatives have been used for cell blocks, primarily buffered formalin, neutral buffered formaldehyde solution, Bouin solution, picric acid fixative, Carnoy fixative and ethanol. ${ }^{[1]}$ The difficulty of recovery and processing of small tissue fragments also has resulted in several unconventional approaches using bacterial agar, plasma thrombin clot, acetone melted paraffin technique, gelling and settling agents and gelatine capsules. ${ }^{[1]}$ In this study by using $10 \%$ alcohol formalin for fixation we got excellent cellularity in the slide.By formalin the proteins are cross linked and a gel is formed which cannot be dissolved in any material used for processing. Thus the cell loss is minimal. ${ }^{\left[{ }^{\prime]}\right.}$ The other methods are inconvenient for routine use and time consuming, they require special attention and care when the material is not easily recognizable. The method also has an advantage of the short 13 hours processing schedule routinely used for small biopsies. The limited exposure to alcohol, xylene and paraffin bath minimizes the artifacts of cellular shrinkage. ${ }^{[1]}$

In our study we found that there is a significant difference between the results obtained by conventional smear as compared to cytocentrifuge and cell block.However the difference between cytocentrifuge and cell block was not significant.Mao YY et al, studied 99 cases of effusion using cytospin and cell block technique. He found that the difference between the two techniques was statistically insignificant. ${ }^{[17]}$ However when coupled with immunohistochemical findings and clinicopathological findings the difference in the diagnosis was statistically significant. Thus Immunohistochemistry when applied on cell block sections, is useful in detection of the primary origins of the tumor cells in effusion fluids. Combination of morphologic examination, immunohistochemical findings and clinicopathologic correlation can further improve the rate of positive diagnosis . ${ }^{[17,12]}$

\section{Conclusion}

Routine centrifuge is not satisfactory in reporting fluids with scant cellularity. Hence for fluids with scant cellularity cytocentrifuge and cell block are useful methods. Also the morphology of the cells were well appreciated by cytocentrifuge and cell block as compared to routine centrifuge, thus aids in accurate diagnosis. In our study the diagnoses which were missed or incompletely diagnosed on routine centrifuge were diagnosed 
accurately by the other two techniques. Also there was statistical difference between the results obtained by the three techniques. Thus cytocentrifuge and cell block proved to be superior method for the study of effusion as compared to routine centrifuge.

\section{References}

[1]. Nathan NA,Narayan E, Smith MM, Horn MJ. Cell block cytology-Improved preparation and its efficacy in diagnostic cytology. Am J ClinPathol 2000;114: 599-606

[2]. Kushwaha R,Shashikala P, Hiremath S, Basavaraj HG. Cells in pleural fluid and their value in differential diagnosis. J Cytol 2008;25:138-43.

[3]. Mair, Dunbar F, Becker PJ, DuPlessis W. Fine Needle Cytology: Is aspiration suction necessary? A study of 100 masses in various sites. ActaCytol 1989;33:809-13.

[4]. Sherwani R, Akhtar K, Abrari A, Hajra S. Pleural effusion cytology as an aid in the diagnosis of pulmonary tuberculosis. J Cytol 2006;23:123-27.

[5]. Gaur DS, Chauhan N, Kusum A, Harsh M, Talekar M. Pleural Fluid Analysis-Role in Diagnosing Pleural Malignancy. J Cytol 2007; $24: 183-88$.

[6]. Udasimath S, Arakeri SU, Karigowdar MH. Diagnostic utility of the cell block method versus the conventional smear study in pleural fluid cytology. J Cytol 2012; 29:11-15

[7]. Bodele AK, Parate SN, Wadadekar AA, Bobhate SK, Munshi MM. Diagnostic utility of cell block preparation in repoting of fluid cytology. J Cytol 2003;20:133-35.

[8]. 8.Thapar M, Mishra RK, Sharma A, Goyal V. Critical analysis of cell block versus smear examination in effusion. J Cytol 2009;26:60-4.

[9]. Stevens MW, Fazzalari NL, Crisp DJ. Lymph node cellular morphology: Comparative study of imprints and cytocentrifuge smears. J ClinPathol 1987;40:751-55.

[10]. Shah P,Deshmukh R. Exfoliative Cytology and Cytocentrifuge Preparation of Oral Premalignant and Malignant Lesions.ActaCytol 2012;56:68-73.

[11]. Moreno MJ,Clayburne G, Schumacher HR. Processing of noninflammatory synovial fluids with hyaluronidase for cytospin preparations improves the accuracy of differential counts. DiagnCytopathol 2000;22:256-58.

[12]. Robertson KC, Dahlberg SE, Edberg SC. Clinical and Laboratory Analyses of Cytospin Prepared Gram Stains for Recovery and Diagnosis of Bacteria from Sterile Body Fluids. J ClinMicrobiol 1992;30:377-80.

[13]. Naylor B. Pleural, Peritoneal fluids. In :Bibbo M. Comprehensive Cytophathology. $1^{\text {st }}$ Ed. Philedelphia :WB Saunders, 1991; 551621 .

[14]. Gieisinger KR, Stanely MW, Raab SS, Silverman JF, Abati A. In: Natasha A. Effusions. Modern Cytopathology.2 $2^{\text {nd }}$ Ed. Philedelphia: Elsevier,2004;258-59.

[15]. Kinni SR. Serous Effuaions. In: Mtichell W. Colour atlas of Differential Diagnosis in Exfoliative and Aspiration Cytopathology. $1^{\text {st }}$ Ed. USA: Williams \& Wilkins, 1999;119-142.

[16]. Dekker A, Bupp PA. Cytology of serous effusions. An investigation into the usefulness of cell blocks versus smears. Am J ClinPathol 1978;70:855-60.

[17]. Mao YY, Yang M, Lui DG, Lin MH, Zhang LQ, Chen ZQ. Evaluation of immunohistochemistry staining and cytologic diagnosis by using cell block sections prepared with effusion fluid cytology specimen. Zhonghua Bing Li XueZaZhi 2009; 38:547-50.

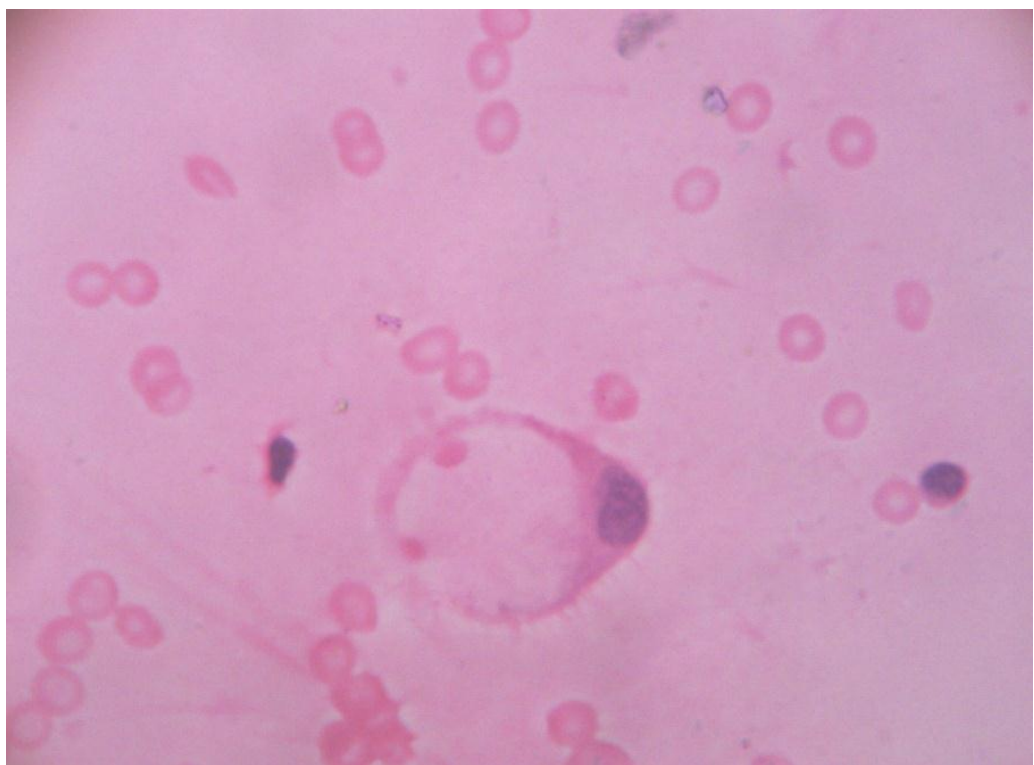

Figure 1 - Photomicrograph showing single signet cell on routine centrifuge in case of signet cell adenocarcinoma.(H\&E, 40X). 


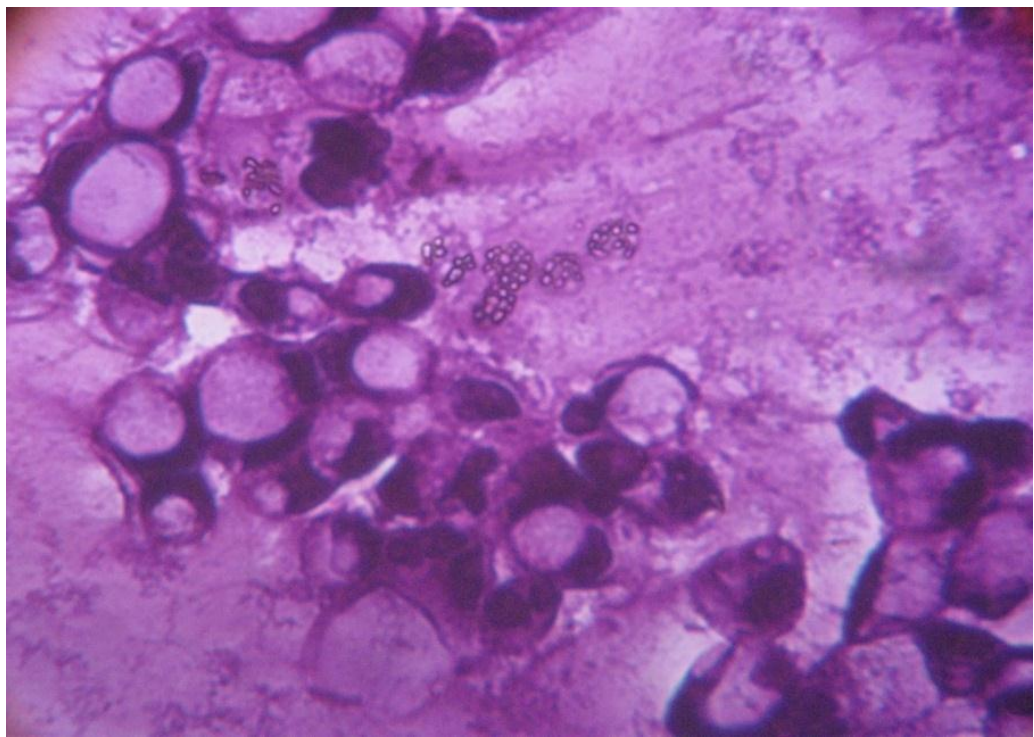

Figure 2 -Photomicrograph showing many signet cells on cytospin in case of signet cell adenocarcinoma.(H\&E, 40X)

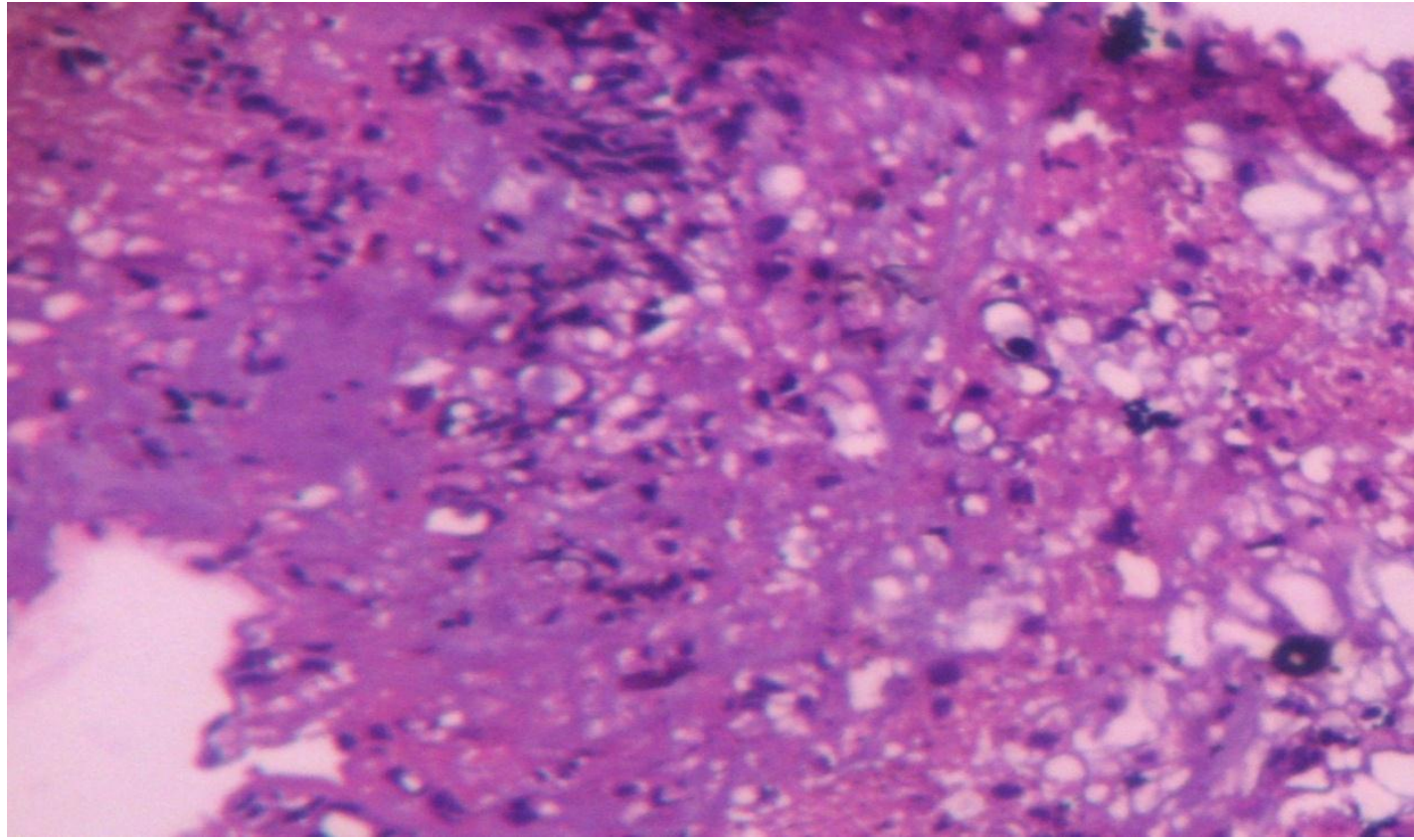

Figure 3 -Photomicrograph showing signet cells on cell block.(H\&E, 10X) 